OPEN ACCESS

Edited by:

Udo Rolle,

Universitätsklinikum Frankfurt,

Germany

Reviewed by:

Christoph Bührer,

Charité Universitätsmedizin Berlin,

Germany

Paolo Ghirri,

Università degli Studi di Pisa, Italy

Rolf Lambert Schlößer,

Universitätsklinikum Frankfurt,

Germany

*Correspondence:

Kristine M. Stangenes

kess@helse-bergen.no

Specialty section:

This article was submitted to

Children and Health,

a section of the journal

Frontiers in Pediatrics

Received: 26 March 2018

Accepted: 31 May 2018

Published: 20 June 2018

Citation:

Stangenes KM, Hysing M, Fevang SK, Elgen IB, Halvorsen T, Markestad T and Bjorvatn B (2018) Prenatal and Neonatal Factors Predicting Sleep Problems in Children Born Extremely

Preterm or With Extremely Low Birthweight. Front. Pediatr. 6:178 doi: 10.3389/fped.2018.00178

\section{Prenatal and Neonatal Factors Predicting Sleep Problems in Children Born Extremely Preterm or With Extremely Low Birthweight}

\author{
Kristine M. Stangenes ${ }^{1 *}$, Mari Hysing ${ }^{2}$, Silje K. Fevang ${ }^{1}$, Irene B. Elgen ${ }^{3}$, \\ Thomas Halvorsen $^{1}$, Trond Markestad ${ }^{1}$ and Bjørn Bjorvatn ${ }^{4,5}$ \begin{abstract}
and Child Welfare, Uni Research Health, Bergen, Norway, ${ }^{3}$ Department of Clinical Medicine, University of Bergen, Bergen, Norway, ${ }^{4}$ Department of Global Public Health and Primary Care, University of Bergen, Bergen, Norway, ${ }^{5}$ Norwegian Competence Center for Sleep Disorders, Haukeland University Hospital, Bergen, Norway
\end{abstract} \\ ${ }^{1}$ Department of Clinical Science, University of Bergen, Bergen, Norway, ${ }^{2}$ Regional Centre for Child and Youth Mental Health
}

Objective: Prematurely born children have been reported to have more sleep problems throughout childhood than children born at term. The aim of this study was to explore if prenatal or neonatal factors can predict sleep problems at age 11 years in children born extremely preterm (EPT).

Method: A prospective observational study of all infants who were born EPT in Norway in 1999 and 2000. Prenatal and neonatal data were collected by all Norwegian obstetric and pediatric departments. Parental questionnaire mapped sleep problems and sleep habits at the age of 11 years.

Results: Of the 372 eligible children, 221 participated. Of those, 28.1\% snored, 27.5\% had difficulty falling asleep or frequent awakenings and $17.2 \%$ suffered from daytime sleepiness. The mean sleep duration was $9.4 \mathrm{~h}$ (range 4.3-11.0 h). Smoking in pregnancy predicted snoring (odds ratio 4.3). Neonatal cerebral hemorrhage and being born small for gestational age predicted difficulty falling asleep or frequent awakenings (odds ratio 2.2 and 2.3). Other morbidities during pregnancy or the newborn period, gestational age or the burden of treatment in the neonatal intensive care unit did not predict sleep problems. None of the studied prenatal or neonatal factors predicted daytime sleepiness or sleep duration $<9 \mathrm{~h}$.

Conclusion: Of numerous prenatal and neonatal factors, only smoking during pregnancy, being born small for gestational age and cerebral hemorrhage predicted sleep problems at 11 years of age among these children born EPT.

Keywords: extremely premature, gestational age, prenatal factors, neonatal factors, sleep problems, sleep characteristics, the medical birth registry of Norway 


\section{INTRODUCTION}

Premature birth in general is associated with an increased risk of experiencing neurodevelopmental impairments, mental health problems, limited respiratory and cardiovascular function and metabolic syndrome. These risks increase with decreasing gestational age (GA) at birth (1-3). Data on more subtle longterm consequences of extremely premature (EPT) birth, e.g., related to sleep, are just starting to emerge since survival after EPT is a relatively new phenomenon (4). Satisfactory sleep is an important part of children's development and quality of life (5), and in general, prematurely born children more commonly experience a variety of sleep problems $(6-9,35)$. Whether children born EPT are at particular risk is not well studied, but we have recently shown that children born EPT more often have sleep problems throughout childhood until 11 years of age than children born at term (10).

It is important to identify early risk factors for adverse outcomes in order to guide families, health care workers and other professionals who will share responsibilities for these children's development. It has been reported that preeclampsia (11), smoking in pregnancy (12), chorioamnonitis and multiple gestation (13) are associated with later sleep disordered breathing, i.e., conditions that provide unusual breathing patterns during sleep (14), in children born premature. However, whether prenatal or neonatal factors can predict other types of sleep problems, and particularly in children born EPT, have not been explored. Furthermore, it is unknown whether sleep problems in childhood or adolescence can be linked to prematurity per se or to specific prenatal and neonatal factors, such as intrauterine growth restriction or treatment and complications during their stay in the neonatal intensive care unit (NICU), e.g., assisted ventilation and cerebral and respiratory morbidities. Since such morbidities as well as EPT per se are associated with a number of later neurodevelopmental and respiratory difficulties (15-17), our hypothesis was that early life experiences may also have a significant impact on specific sleep related problems in children born EPT. Our aim was, therefore, to explore to what extent prenatal or neonatal factors may predict specific sleep problems at 11 years of age.

\section{MATERIALS AND METHODS}

\section{Population}

The study population was a national cohort of all children born EPT $(n=372)$ in Norway in 1999 and 2000. EPT was defined as gestational age (GA) $<28$ completed weeks or birthweight (BW) $<1,000 \mathrm{~g}$. The children were prospectively followed from birth and were assessed for sleep problems at 11 years of age. The parents gave written informed consent.

\section{Prenatal and Neonatal Factors}

All obstetric and pediatric departments in Norway participated, and the study was coordinated by the Medical Birth Registry of Norway (MBRN). Local obstetricians and neonatologists recorded data on maternal health, pregnancy, delivery and diagnoses and treatments in the NICU, and the MBRN provided additional information. Being born small for gestational age (SGA) was defined as birthweight below 10th percentile (18). Details on the definitions of diseases, complications and treatment in the NICU have been published (19, 20). All infants had repeated cerebral ultrasound scans and examinations by ophthalmologists during the hospital stay. An illness severity score which is an index of early disease severity (21) was calculated for each child. It was computed from three components of the Clinical Risk Index for babies namely, the lowest and highest fractional oxygen requirements and the largest base deficit during the first $12 \mathrm{~h}$ of life (22). In order to explore whether extensive medical treatment at the NICU would predict sleep problems, we created a variable that identified children who had received at least one of three common extensive medical treatments; mechanical ventilation $>40$ days, necrotizing enterocolitis or $\geq$ four courses of antibiotic treatment.

\section{Sleep Problems and Sleep Habits at 11 Years of Age}

Current sleep problems were assessed by parental report, i.e., whether their child had difficulty falling asleep or frequent awakenings, snored, gasped for air or stopped breathing when asleep, and if the child had trouble breathing at night. They were also asked if the child had daytime sleepiness. The response options to these questions were "Not true," "Partly true," and "Absolutely true." In our analyses, the variables "Partly true" and "Absolutely true" were merged. Sleep habits were measured by the following items: At what time their child went to bed and got up on weekdays, how long time it took from going to bed until falling asleep (sleep onset latency) and how long time the child was awake during the night after sleep onset. We calculated total sleep duration as time in bed minus sleep onset latency and time awake after sleep onset. In accordance with recently published guidelines, recommended sleep duration at 11 years was defined as $9-11 \mathrm{~h}$ (23).

\section{Statistical Analyses}

For each specific sleep outcome variable (yes or no), the predictors were compared as means and standard deviations (SD) or as proportions using Student's $t$-tests, Chi-square tests or Fisher's exact tests, as appropriate. Odds ratios and $95 \%$ confidence intervals (CI) were calculated both unadjusted and after adjusting for sex, single parenthood and maternal education (dichotomized as less than a 3-year college education or not) in logistic regression analyses. Significance level was set at $\alpha$ level 0.05 .

\section{Ethics}

The study was approved by the Regional Committee on Medical Research Ethics (2009-2271) and the Norwegian Data Inspectorate. The parents gave written informed consent in accordance with the Declaration of Helsinki. 


\section{RESULTS}

\section{Sample Characteristics}

Of 372 eligible children, sleep data were available for 221 (59\%) at 11 years. The mothers answered the questionnaire in $64.7 \%$ $(n=139)$ of the cases, the fathers in $3.7 \%(n=8)$, both parents in $30.7 \%(n=66)$ and the child's foster mother in $0.9 \%(n=2)$. The sociodemographic, prenatal and neonatal characteristics are listed in Table 1. The significant differences in family background and demographic characteristics between those with and without sleep data were a higher proportion of girls ( 50 vs. $39 \%, p=0.049$ ) and of mothers with higher education registered during the pregnancy ( 48 vs. $34 \%, p=0.009$ ) among those with sleep data.

\section{Sleep Problems and Sleep Habits in EPT Children}

Difficulty falling asleep or frequent awakenings was reported for $27.5 \%$, snoring for $28.1 \%$ and daytime sleepiness for $17.2 \%$ of the children (Table 2). Only three children had breathing problems and two gasped for air when asleep (Table 2). Predictors of these outcomes were, therefore, not examined, but four of these five children also snored and were thereby included in the group of snorers. The mean time in bed was $10.2 \mathrm{~h}(S D=0.5 \mathrm{~h}$; range $9.0-12.0 \mathrm{~h})$ and the mean sleep duration $9.4 \mathrm{~h}(S D=1.0 \mathrm{~h}$; range 4.3-11.0 h). The sleep duration was within the recommended 9$11 \mathrm{~h}$ for $75.3 \%$ of the children, within $7-8 \mathrm{~h}$ (possibly adequate) for $22.3 \%$ and $<7 \mathrm{~h}$ (less than recommended) for $2.4 \%$ of the children. None of the children slept more than recommended. There were no significant differences in the prevalence of difficulty falling asleep or frequent awakenings ( 27.2 vs. $28.0 \%$, $p=0.9$ ), snoring ( 26.2 vs. $34.0 \%, p=0.3$ ), daytime sleepiness (18.8 vs. $12.2 \%, p=0.4$ ) or sleep duration $<9 \mathrm{~h}$ (78.2 vs. $66.7 \%$, $p=0.1)$ at the age of 11 years between the groups of children born before GA 28 weeks and those born with GA 28-32 weeks.

\section{Prenatal and Neonatal Predictors of Sleep Problems}

Being born SGA and neonatal cerebral hemorrhage (subependymal/ intraventricular hemorrhage) were the only prenatal and neonatal factors that significantly predicted difficulty falling asleep or frequent awakenings, i.e., $43 \%$ of SGA vs. $25 \%$ ( $p=0.014$ ) of non-SGA children, and $42 \%$ of children with cerebral hemorrhage vs. $24 \%$ of those without hemorrhage $(p=0.012$, Table 3$)$. The respective odds ratios $(95 \% \mathrm{CI})$ were 2.3 $(1.2-4.4)$ and $2.3(1.2-4.6)$ and did not differ after adjustments for sex, single parenthood and maternal education (Table 3 ). When restricting analyses to children with $\mathrm{GA} \leq 27$, SGA still predicted difficulty falling asleep or frequent awakenings $(p=0.001)$ (data not shown).

Smoking, both during early and end of pregnancy, significantly predicted snoring, i.e., 37 vs. $14 \%(p=0.001)$ for early and 24 vs. $8 \%(p=0.017)$ for late pregnancy. The respective odds ratios $(95 \% \mathrm{CI})$ were 3.5 (1.6-7.7) and $3.4(1.2-$ 9.6) and did not differ significantly after adjustments (Table 4). The predictive value of intrauterine cigarette exposures for later snoring remained unchanged after including the parents' current
TABLE 1 | Characteristics of the 221 children who were born extremely preterma in Norway in 1999-2000 and participated in the follow-up at 11 years of age.

\begin{tabular}{|c|c|}
\hline FAMILY BACKGROUND & $\%(n)$ \\
\hline Single parent & $14(30)$ \\
\hline Higher education mother ${ }^{\mathrm{b}}$ & $55(119)$ \\
\hline Higher education father ${ }^{b}$ & $40(86)$ \\
\hline DEMOGRAPHIC CHARACTERISTICS & Mean (MIN-MAX) \\
\hline Gestational age, weeks & $26.6(23-32)$ \\
\hline \multirow[t]{2}{*}{ Birth weight, grams } & $868(450-1370)$ \\
\hline & $\%(n)$ \\
\hline Boy & $50(111)$ \\
\hline Girl & $50(110)$ \\
\hline \multicolumn{2}{|l|}{ IN UTERO EXPOSURES } \\
\hline Preeclampsia/eclampsia & $24(52)$ \\
\hline Small for gestational age ${ }^{C}$ & $28(61)$ \\
\hline Prenatal steroids & $19(41)$ \\
\hline Infection in amnion cavity & $10(23)$ \\
\hline Smoking-start of pregnancy & $21(39)$ \\
\hline Smoking-end of pregnancy & $13(19)$ \\
\hline \multicolumn{2}{|l|}{ BIRTH TYPE } \\
\hline Cesarean section & $69(152)$ \\
\hline \multicolumn{2}{|l|}{ PERIPARTUM RESUSCITATION } \\
\hline Apgar $<5$ after 5 min & $6(12)$ \\
\hline Intubated & $27(57)$ \\
\hline IIness severity score 4 th quartile ${ }^{d}$ & $22(45)$ \\
\hline \multicolumn{2}{|l|}{ RESPIRATORY MORBIDITY } \\
\hline Mechanical ventilation (yes) & $84(180)$ \\
\hline Days on mechanical ventilation Mean (min-max) & $11(1-113)$ \\
\hline Oscillation & $20(40)$ \\
\hline Postnatal steroids for lung disease & $29(64)$ \\
\hline Theophylline/Caffeine & $96(204)$ \\
\hline Patent ductus arteriosus, surgery treated & $12(26)$ \\
\hline \multicolumn{2}{|l|}{ NEUROLOGIC INJURY } \\
\hline Subependymal/intraventricular hemorrhage & $30(65)$ \\
\hline Retinopathy of prematurity & $25(56)$ \\
\hline Pathological findings by ophthalmologist at discharge & $10(15)$ \\
\hline \multicolumn{2}{|l|}{ OTHER COMPLICATIONS/TREATMENT } \\
\hline Necrotizing enterocolitis & $5(12)$ \\
\hline Extensive medical treatment ${ }^{\mathrm{e}}$ & $14(30)$ \\
\hline Congenital malformations, syndromes or metabolic diseases & $4(9)$ \\
\hline
\end{tabular}

${ }^{a}$ Gestational age $<28$ weeks or birth weight $<1,000 \mathrm{~g}$.

${ }^{b}$ College or university education when the child was 11 year old.

${ }^{c}$ Small for gestational age: birthweights < 10th percentile.

dIllness severity score-computed from 3 components of the Clinical Risk Index for Babies, namely, the lowest and highest fractional oxygen requirements and the largest base deficit during the first $12 \mathrm{~h}$ of life.

${ }^{e}$ Extensive medical treatment defined as one of the following conditions: respirator more than 40 days, necrotizing enterocolitis or four or more antibiotic-treated infections.

smoking habits and the child's body mass index at 11 years in the adjusted analysis (data not shown).

There were no statistically significant predictors of sleep duration $<9 \mathrm{~h}$ or daytime sleepiness (data not shown). None of the factors related to the severity of early lung disease, such as treatment modalities and duration of treatment for lung disease, 
TABLE 2 | Prevalence of parent reported sleep problems at age 11 years in children born extremely preterm ${ }^{\mathrm{a}}$ in Norway in 1999-2000.

\begin{tabular}{lccc}
\hline & $\begin{array}{c}\text { Not true \% } \\
(\boldsymbol{n})\end{array}$ & $\begin{array}{c}\text { Partly true } \\
\%(\boldsymbol{n})\end{array}$ & $\begin{array}{c}\text { Absolutely } \\
\text { true \% (n) }\end{array}$ \\
\hline $\begin{array}{l}\text { Difficulty falling asleep } \\
\text { or frequent awakenings }\end{array}$ & $72.6(143)$ & $16.8(33)$ & $10.7(21)$ \\
$\begin{array}{l}\text { Snores } \\
\begin{array}{l}\text { Gasps for air or stops } \\
\text { breathing when asleep }\end{array}\end{array}$ & $\begin{array}{l}71.9(143) \\
\begin{array}{l}\text { Difficulty breathing at } \\
\text { night }\end{array}\end{array}$ & $23.1(46)$ & $5.0(10)$ \\
Daytime sleepiness & $98.5(194)$ & $0.5(1)$ & $0.5(1)$ \\
\hline
\end{tabular}

${ }^{a}$ Gestational age $<28$ weeks or birth weight $<1,000 \mathrm{~g}$.

severity of bronchopulmonary dysplasia, or extensive medical treatment in the NICU predicted sleep problems at the age of 11 years (Tables 3, 4).

\section{DISCUSSION}

In this national cohort of children born EPT we found that $28.1 \%$ snored, $27.5 \%$ had difficulty falling asleep or frequent awakenings, $17.2 \%$ experienced daytime sleepiness and $24.7 \%$ did not get the recommended sleep duration. Smoking was the only predictor of snoring, and SGA birth and neonatal cerebral hemorrhage were the only predictors of difficulty falling asleep and frequent awakenings.

Our hypothesis was that several early life experiences in children born EPT would affect sleep at 11 years of age, in particular long term consequences related to early cerebral and respiratory morbidity. The limited significance of early events and exposures was remarkable, in particular the lack of association with the extensive and intrusive treatments that the EPT infants encounter. Similarly, studies have suggested that such neonatal exposures did not predict psychiatric disorders in EPT children $(24,25)$. Sleep and mental health are closely linked and these studies should therefore be seen in context (26).

Our finding that smoking in pregnancy was a predictor of snoring is in agreement with a Finnish study that examined young adults who had a birth weight $<1,500 \mathrm{~g}$ (12). Furthermore, a study of children born at term also found that smoking in pregnancy predicted childhood snoring (27). Combined, these studies may suggest that exposure to smoking in pregnancy has a negative effect on respiratory function independent of GA at birth, but that the stresses of prematurity may have an additive effect. The most frequent movement of the fetus during the second trimester is sucking (28). It is hypothesized that sucking is central for oral-facial growth and that extreme premature birth disturbs this process and thereby affects the development of both oral facial anatomy and muscular tone. This may contribute to pediatric sleep related breathing disorders, i.e., snoring (29). It is also a possibility that smoking in pregnancy may affect later physiological regulation, including sleep regulation $(30,31)$.

The prevalence of snoring (28.1\%) in our EPT population was markedly higher than the prevalence of $7.5 \%$ in a meta-analysis of parent reported snoring in unselected children aged $0-18$ years (32). Rosen et al. found that $21 \%$ of children who were born at a mean GA of 31 weeks compared to $14 \%$ of children born at term snored at the age of $8-11$ years $(p=0.0049)(6)$. Together, these data may suggest that the prevalence of snoring increases with decreasing GA. The high prevalence of snoring in our study was unrelated to most pre-and neonatal factors suggesting that the general stresses of extra-uterine life of EPT birth may explain the excess risk. Reversed causality may also be a factor since studies have shown that sleep apnea in pregnant women may increase the risk of spontaneous premature birth (33). Sleep apnea and snoring are associated (34) which may imply a genetic predisposition. We were not able to explore this possibility since we had no information on snoring or other sleep disorders in the parents. Snoring can be a symptom or possibly a precursor of sleep disordered breathing (34).

Previous studies have shown that children born prematurely have an increased risk of sleep disordered breathing in childhood (35) and as an adult (12), and that they may also be particularly vulnerable to the negative sequelae of sleep disordered breathing in childhood (36). In general, sleep disordered breathing in childhood is a risk factor for impaired neurocognitive performance, behavioral problems, externalizing symptoms and inattention (37-42). The American Academy of Pediatrics therefore suggests that all children should be screened for snoring, and that high-risk patients should be referred to a specialist (43). The prevalence of sleep disordered breathing during childhood in children born EPT is unknown, but may be high judged from the high prevalence of snoring. Our findings indicate that snoring is a significant problem in preterm born children, and underline that more studies are needed to map the explicit risks and possible consequences of this condition in children born EPT.

To our knowledge, our findings that neonatal cerebral hemorrhage and SGA birth predicted difficulty falling asleep or frequent awakenings at 11 years of age are novel. Wang et al. found no association between neonatal risk factors, including grade III-IV intraventricular hemorrhage, and restless sleep in children born EPT at the age of 18-22 months (44). However, our findings were not unexpected since both cerebral hemorrhage and SGA are known risk factors for adverse neurodevelopmental outcomes $(16,45)$, and since we previously reported that a variety of sleep problems are more prevalent in EPT children with neurodevelopmental disabilities (10). Previous studies show that to be SGA add to the risk for several types of morbidity for EPT children (46). The fact that we found that SGA predicts difficulty falling asleep or frequent awakenings at the age of 11 years confirms this group's increased vulnerability. Difficulty falling asleep or frequent awakenings was reported in $27.5 \%$ of the EPT children in our cohort as opposed to a prevalence of $12.7 \%$ in an unselected cohort of 11-13 year-old Norwegian children (47). A previous study using polysomnography also reported increased number of awakenings in children born prematurely (GA < 32weeks) compared to children born at term (7).

According to the parents, $17.2 \%$ of the EPT children suffered from daytime sleepiness. Rosen et al. found a lower prevalence 
TABLE 3 | Prenatal and neonatal factors predicting difficulty falling asleep or frequent awakenings at 11 years of age among children born extremely preterma .

\begin{tabular}{|c|c|c|c|c|c|}
\hline & \multicolumn{2}{|c|}{$\begin{array}{l}\text { Difficulty falling asleep or } \\
\text { frequent awakenings }\end{array}$} & \multirow[b]{2}{*}{$p$-value ${ }^{1}$} & \multirow[b]{2}{*}{$\begin{array}{l}\text { Unadjusted OR (95\% } \\
\mathrm{CI})(n=133-197)\end{array}$} & \multirow[b]{2}{*}{$\begin{array}{l}\text { Adjusted }{ }^{\mathrm{b}} \text { OR }(95 \% \\
\mathrm{Cl})(n=132-196)\end{array}$} \\
\hline & $\begin{array}{l}\text { No }(n=143) \\
\%(n)\end{array}$ & $\begin{array}{l}\text { Yes }(n=54) \\
\%(n)\end{array}$ & & & \\
\hline \multicolumn{6}{|l|}{ DEMOGRAPHIC CHARACTERISTICS } \\
\hline Gestational age group, weeks & & & 0.6 & & \\
\hline $23-25$ & $20(28)$ & $26(14)$ & & $1.3(0.5-3.1)$ & $1.3(0.5-3.2)$ \\
\hline $26-27$ & $55(79)$ & $48(26)$ & & $0.9(0.4-1.8)$ & $1.0(0.4-2.1)$ \\
\hline 28-32 (reference) & $25(36)$ & $26(14)$ & & & \\
\hline Single pregnancy (yes) & 78 (112) & $76(41)$ & 0.7 & $0.9(0.4-1.8)$ & $0.9(0.4-2.0)$ \\
\hline \multicolumn{6}{|l|}{ IN UTERO EXPOSURES } \\
\hline Preeclampsia/eclampsia (yes) & $23(33)$ & $26(14)$ & 0.7 & $1.2(0.6-2.4)$ & $1.2(0.6-2.4)$ \\
\hline Small for gestational age ${ }^{\mathrm{C}}$ (yes) & $25(36)$ & $43(23)$ & 0.014 & $2.3(1.2-4.4)$ & $2.2(1.1-4.2)$ \\
\hline Prenatal steroids (yes) & $20(28)$ & $17(9)$ & 0.7 & $0.8(0.4-1.9)$ & $0.9(0.4-2.0)$ \\
\hline Infection in amnion cavity (yes) & $11(15)$ & $9(5)$ & 0.8 & $0.9(0.3-2.5)$ & $1.1(0.4-3.2)$ \\
\hline Smoking - start of pregnancy (yes) & $21(25)$ & $20(9)$ & 0.9 & $0.9(0.4-2.2)$ & $0.8(0.3-2.1)$ \\
\hline Smoking-end of pregnancy (yes) & $12(11)$ & $16(6)$ & 0.6 & $1.4(0.5-4.2)$ & $1.5(0.5-4.5)$ \\
\hline \multicolumn{6}{|l|}{ BIRTH TYPE } \\
\hline Cesarean (yes) & $68(97)$ & $70(38)$ & 0.7 & $1.1(0.6-2.2)$ & $1.1(0.6-2.3)$ \\
\hline \multicolumn{6}{|l|}{ PERIPARTUM RESUSCITATION } \\
\hline Apgar < 5 after 5 min (yes) & $4(6)$ & $6(3)$ & 0.7 & $1.3(0.3-5.6)$ & $1.4(0.3-6.0)$ \\
\hline Intubation (yes) & $72(99)$ & $67(34)$ & 0.5 & $0.8(0.4-1.5)$ & $0.8(0.4-1.6)$ \\
\hline Illness severity score 4th quartiled (yes) & $20(27)$ & $28(14)$ & 0.3 & $1.5(0.7-3.2)$ & $1.6(0.7-3.3)$ \\
\hline \multicolumn{6}{|l|}{ RESPIRATORY MORBIDITY } \\
\hline Mechanical ventilation (yes) & $82(115)$ & $84(43)$ & 0.7 & $1.2(0.5-2.8)$ & $1.2(0.5-2.8)$ \\
\hline Days on mechanical ventilation $>10$ & $24(34)$ & $24(13)$ & 1.0 & $1.0(0.5-2.1)$ & $1.2(0.5-2.8)$ \\
\hline Oscillation (yes) & $20(25)$ & $24(11)$ & 0.5 & $1.3(0.6-3.0)$ & $1.2(0.5-2.8)$ \\
\hline Postnatal steroids for lung disease (yes) & $28(39)$ & $30(16)$ & 0.7 & $1.1(0.6-2.3)$ & $1.1(0.6-2.3)$ \\
\hline Theophylline / Caffeine (yes) & $95(130)$ & $98(50)$ & 0.7 & $2.7(0.3-22)$ & $2.5(0.3-20.6)$ \\
\hline Discharged from hospital with oxygen (yes) & $9(13)$ & $9(5)$ & 1.0 & $1.0(0.4-3.0)$ & $1.0(0.3-3.1)$ \\
\hline Patent ductus arteriosus, surgery treated (yes) & $11(15)$ & $15(8)$ & 0.4 & $1.5(0.6-3.7)$ & $0.7(0.3-1.8)$ \\
\hline \multicolumn{6}{|l|}{ NEUROLOGIC INJURY } \\
\hline Subependymal or intraventricular hemorrhage (yes) & $24(34)$ & $42(22)$ & 0.012 & $2.3(1.2-4.6)$ & $2.3(1.1-4.5)$ \\
\hline Retinopathy of prematurity (yes) & $25(36)$ & $24(13)$ & 0.9 & $0.9(0.5-1.9)$ & $0.9(0.4-1.9)$ \\
\hline Pathological findings by ophthalmologist at discharge (yes) & $12(11)$ & $8(3)$ & 0.5 & $0.6(0.2-2.3)$ & $0.6(0.2-2.3)$ \\
\hline \multicolumn{6}{|l|}{ OTHER COMPLICATIONS/TREATMENT } \\
\hline Necrotizing enterocolitis (yes) & $6(8)$ & $7(4)$ & 0.7 & $1.4(0.4-4.7)$ & $1.1(0.3-4.1)$ \\
\hline Extensive medical treatment ${ }^{\mathrm{e}}$ (yes) & $13(18)$ & $22(12)$ & 0.09 & $1.9(0.8-4.5)$ & $1.8(0.8-4.1)$ \\
\hline Congenital malformations, syndromes or metabolic diseases & $5(7)$ & $4(2)$ & 1.0 & $0.8(0.2-4.0)$ & $0.7(0.1-3.5)$ \\
\hline
\end{tabular}

${ }^{a}$ Extremely premature (EP): gestational age $<28$ weeks or birth weight $<1,000 \mathrm{~g}$.

${ }^{b}$ Adjusted for sex, single parent and higher education mother. ${ }^{1}$ Chi-square or Fisher-exact test.

c Small for gestational age: birthweights < 10th percentile.

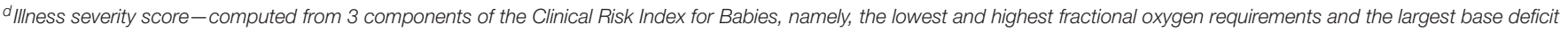
during the first $12 \mathrm{~h}$ of life.

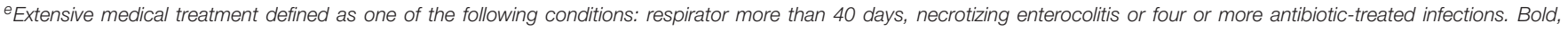
$p$-values < 0.05; $n$, number; $S D$, standard deviation; OR, odds ratio; Mean diff.; mean difference.

in children born premature and no difference between the premature and a reference group born at term (6 vs. $7 \%$ ) (6). However, their children were more mature at birth (mean gestational age 31 weeks) compared to our cohort. In another population-based unselected study of American children the parent-reported prevalence of daytime sleepiness was 15\% (48), which is similar to what we found. Daytime sleepiness may therefore not be a problem related to extreme prematurity. This notion is strengthened by our findings that none of the prenatal or neonatal factors predicted daytime sleepiness.

None of the prenatal and neonatal factors predicted less than recommended sleep duration. Sleeping less than recommended is 
TABLE 4 | Prenatal and neonatal factors predicting snoring at 11 years of age among children born extremely preterm ${ }^{\mathrm{a}}$.

\begin{tabular}{|c|c|c|c|c|c|}
\hline & \multicolumn{2}{|c|}{ Snoring } & \multirow[b]{2}{*}{$p$-value ${ }^{1}$} & \multirow[b]{2}{*}{$\begin{array}{l}\text { Unadjusted OR (95\% } \\
\text { CI) }(n=133-199)\end{array}$} & \multirow[b]{2}{*}{$\begin{array}{l}\text { Adjusted OR }{ }^{\mathrm{b}}(95 \% \\
\mathrm{Cl})(n=133-198)\end{array}$} \\
\hline & $\begin{array}{l}\text { No }(n=143) \\
\%(n)\end{array}$ & $\begin{array}{l}\text { Yes }(n=56) \\
\%(n)\end{array}$ & & & \\
\hline \multicolumn{6}{|l|}{ DEMOGRAPHIC CHARACTERISTICS } \\
\hline Gestational age group, weeks & & & 0.3 & & \\
\hline $23-25$ & $20(29)$ & $25(14)$ & & $0.9(0.4-2.2)$ & $1.0(0.4-2.3)$ \\
\hline $26-27$ & $57(81)$ & $45(25)$ & & $0.6(0.3-1.3)$ & $0.7(0.3-1.4)$ \\
\hline 28-32 (reference) & $23(33)$ & $30(17)$ & & & \\
\hline Single pregnancy (yes) & $78(112)$ & $73(41)$ & 0.5 & $0.8(0.4-1.5)$ & $0.8(0.4-1.6)$ \\
\hline \multicolumn{6}{|l|}{ IN UTERO EXPOSURES } \\
\hline Preeclampsia/eclampsia (yes) & $27(38)$ & $16(9)$ & 0.1 & $0.5(0.2-1.2)$ & $0.5(0.2-1.2)$ \\
\hline Small for gestational age ${ }^{\mathrm{C}}$ (yes) & $31(44)$ & $27(15)$ & 0.6 & $0.8(0.4-1.6)$ & $0.8(0.4-1.6)$ \\
\hline Prenatal steroids (yes) & $18(26)$ & $19(10)$ & 0.9 & $1.0(0.5-2.3)$ & $1.0(0.5-2.3)$ \\
\hline Infection in amnion cavity (yes) & $11(15)$ & $9(5)$ & 0.7 & $0.8(0.3-2.4)$ & $1.2(0.4-3.4)$ \\
\hline Smoking-start of pregnancy & $14(17)$ & $37(17)$ & 0.001 & $3.5(1.6-7.7)$ & $4.3(1.8-10)$ \\
\hline Smoking-end of pregnancy & $8(8)$ & $24(9)$ & 0.017 & $3.4(1.2-9.6)$ & $4.3(1.4-13)$ \\
\hline \multicolumn{6}{|l|}{ BIRTH TYPE } \\
\hline Cesarean (yes) & $69(98)$ & $68(38)$ & 0.9 & $0.9(0.5-1.9)$ & $0.9(0.5-1.9)$ \\
\hline \multicolumn{6}{|l|}{ PERIPARTUM RESUSCITATION } \\
\hline Apgar $<5$ after 5 min & $3(4)$ & $7(4)$ & 0.2 & $2.7(0.7-11)$ & $3.1(0.7-12.9)$ \\
\hline Intubation (yes) & $30(40)$ & $28(15)$ & 0.8 & $1.0(0.5-2.1)$ & $1.1(0.5-2.3)$ \\
\hline Illness severity score 4 th quartile ${ }^{d}$ (yes) & $23(32)$ & $17(9)$ & 0.4 & $0.7(0.3-1.6)$ & $0.7(0.3-1.6)$ \\
\hline \multicolumn{6}{|l|}{ RESPIRATORY MORBIDITY } \\
\hline Mechanical ventilation (yes) & $84(118)$ & $81(42)$ & 0.6 & $0.8(0.4-1.9)$ & $0.8(0.4-1.9)$ \\
\hline Days on mechanical ventilation $>10$ & $26(37)$ & $20(11)$ & 0.4 & $0.7(0.3-1.5)$ & $0.7(0.3-1.5)$ \\
\hline Oscillation (yes) & $23(30)$ & $15(7)$ & 0.3 & $0.6(0.2-1.5)$ & $0.6(0.2-1.4)$ \\
\hline Postnatal steroids for lung disease (yes) & $30(43)$ & $26(14)$ & 0.6 & $0.8(0.4-1.6)$ & \\
\hline Theophylline / Caffeine (yes) & $96(131)$ & $94(51)$ & 0.6 & $0.7(0.2-2.8)$ & $0.6(0.1-2.7)$ \\
\hline Discharged from hospital with oxygen (yes) & $11(16)$ & $4(2)$ & 0.09 & $0.3(0.07-1.3)$ & $3.6(0.8-16.3)$ \\
\hline Patent ductus arteriosus, surgery treated (yes) & $12(17)$ & $14(8)$ & 0.7 & $1.2(0.5-3.0)$ & $0.8(0.3-2.0)$ \\
\hline \multicolumn{6}{|l|}{ NEUROLOGIC INJURY } \\
\hline Subependymal or intraventricular hemorrhage (yes) & $26(37)$ & $35(19)$ & 0.3 & $1.5(0.8-2.9)$ & $1.5(0.7-2.9)$ \\
\hline Retinopathy of prematurity (yes) & $25(36)$ & $21(12)$ & 0.6 & $0.8(0.4-1.7)$ & $0.8(0.4-1.6)$ \\
\hline Pathological findings by ophthalmologist at discharge (yes) & $7(7)$ & $17(6)$ & 0.1 & $2.6(0.8-8.3)$ & $2.4(0.7-7.9)$ \\
\hline \multicolumn{6}{|l|}{ OTHER COMPLICATIONS / TREATMENT } \\
\hline Necrotizing enterocolitis (yes) & $5(7)$ & $9(5)$ & 0.3 & $1.9(0.6-6.3)$ & $1.8(0.5-5.9)$ \\
\hline Extensive medical treatment ${ }^{\mathrm{e}}$ (yes) & $15(21)$ & $16(9)$ & 0.8 & $1.1(0.5-2.6)$ & $1.0(0.4-2.5)$ \\
\hline Congenital malformations, syndromes or metabolic diseases & $5(7)$ & $4(2)$ & 0.8 & $0.8(0.2-3.8)$ & $0.6(0.1-3.3)$ \\
\hline
\end{tabular}

${ }^{a}$ Gestational age $<28$ weeks or birth weight $<1,000 \mathrm{~g}$.

${ }^{b}$ Adjusted for sex, single parent and higher education mother. ${ }^{1}$ Chi-square or Fisher exact test.

cSmall for gestational age: birthweights < 10th percentile.

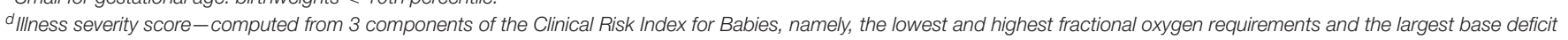
during the first $12 \mathrm{~h}$ of life.

${ }^{e}$ Extensive medical treatment defined as one of the following conditions: respirator more than 40 days, necrotizing enterocolitis or four or more antibiotic-treated infections.Bold, $p$-values < 0.05; $n$, number; SD, standard deviation; OR, odds ratio; Mean diff.; mean difference.

shown to have several negative consequences for children $(49,50)$ and, in adults, long sleep duration is also associated with poor health (51).We previously reported that the EPT children have longer sleep duration than a control group (10). However, in that report we used a slightly different definition of sleep duration, where we did not take into account time awake during nightly awakenings.
Strengths of this study included the national longitudinal population-based design of the EPT cohort. The limited response rate at follow-up was a weakness, as in most population based follow-up studies. This can lead to selection bias, but we have previously shown that the assessed children were probably representative of all the survivors at 11 years of age (52). It would have been desirable to compare the prevalence of sleep 
problems in our EPT group with that of children born at term. Unfortunately, we had no control group for comparison. In our previous study, we used a control group to compare the prevalence of sleep problems in childhood (10). Unfortunately, the questions that form the basis of the present article were not included in the questionnaire to this control group. However, the main intention of the study was not to map the prevalence of sleep problems, but to explore which factors may predict sleep problems in children born EPT. The majority of these factors are unique to children born EPT, and not relevant for a control group.

We did not ask the children themselves about their sleep. It may be difficult for parents of 11 year old children to answer some of the questions, for example, nightly awakenings and daytime sleepiness. Another limitation relates to the many prenatal and neonatal factors that were included in the analyses. We did not adjust for multiple testing (type 1 errors), thus the results need to be interpreted with caution. We adjusted for single parenthood, maternal education and sex in all our analyses, and in addition for the parents' smoking habits and the child's BMI at 11 years of age when exploring predictive factors for snoring. We may, however, have overlooked other clinically significant confounders.

\section{CONCLUSIONS}

Our main finding was that a multitude of factors related to morbidity and treatment in the prenatal or neonatal period did not predict sleep problems at age 11 years in children born EPT. Smoking in pregnancy predicted snoring, and SGA birth and neonatal cerebral hemorrhage predicted difficulty falling asleep or frequent awakenings.

\section{DATA AVAILABILITY STATEMENTS}

According to the approvals granted for this study by The Regional Committee on Medical Research Ethics and The Norwegian Data Inspectorate, the data files are to be stored

\section{REFERENCES}

1. Bhutta AT, Cleves MA, Casey PH, Cradock MM, Anand KJ. Cognitive and behavioral outcomes of school-aged children who were born preterm: a meta-analysis. JAMA (2002) 288:728-37. doi: 10.1001/jama.288. 6.728

2. Aarnoudse-Moens CS, Weisglas-Kuperus N, Van Goudoever JB, Oosterlaan J. Meta-analysis of neurobehavioral outcomes in very preterm and/or very low birth weight children. Pediatrics (2009) 124:717-28. doi: $10.1542 /$ peds.2008-2816

3. Raju TNK, Buist AS, Blaisdell CJ, Moxey-Mims M, Saigal S. Adults born preterm: a review of general health and system-specific outcomes. Acta Paediatr. (2017) 106:1409-37. doi: 10.1111/apa. 13880

4. Johnson S, Marlow N. Charting the survival, health and development of extremely preterm infants: EPICure and beyond. Paediatr Child Health (2016) 26:498-504. doi: 10.1016/j.paed.2016. 08.003

5. Dewald JF, Meijer AM, Oort FJ, Kerkhof GA, Bogels SM. The influence of sleep quality, sleep duration and sleepiness on school performance in children properly and in line with the Norwegian Law of Privacy Protection. The data file is not made publically available as this might compromise the respondents' privacy, particularly as some of our participating centers are small and the number of extremely preterm births very limited. Moreover, the data file is currently used by other researchers in our group to prepare future research papers. A subset of the data file with anonymized data may be made available to interested researchers upon reasonable request to Thomas Halvorsen (thomas.halvorsen@helsebergen.no) and providing permission from The Norwegian Data Inspectorate and the other members of our research group.

\section{AUTHOR CONTRIBUTIONS}

KS secured the data set, contributed to the design of the study and to the analysis strategy, carried out all the analyses and drafted the initial manuscript. TM coordinated and supervised data collection for the extremely premature children and contributed to the design of the study and to the analysis strategy. $\mathrm{MH}, \mathrm{SF}, \mathrm{IE}, \mathrm{TH}$, and $\mathrm{BB}$ contributed to the design of the study and to the analysis strategy. All authors revised the manuscript and approved the final manuscript as submitted and agree to be accountable for all aspects of the work.

\section{FUNDING}

This research was supported by the Norwegian Extra Foundation for Health and Rehabilitation through the Premature Society.

\section{ACKNOWLEDGMENTS}

Parts of the results are previously presented as a poster at the congress World Sleep 2017 in Prague, Czech Republic. and adolescents: a meta-analytic review. Sleep Med Rev. (2010) 14:179-89. doi: 10.1016/j.smrv.2009.10.004

6. Rosen CL, Larkin EK, Kirchner HL, Emancipator JL, Bivins SF, Surovec SA, et al. Prevalence and risk factors for sleep-disordered breathing in 8- to 11year-old children: association with race and prematurity. J Pediatr. (2003) 142:383-9. doi: $10.1067 / \mathrm{mpd} .2003 .28$

7. Hagmann-Von Arx P, Perkinson-Gloor N, Brand S, Albert D, Holsboer-Trachsler E, Grob A, et al. In school-age children who were born very preterm sleep efficiency is associated with cognitive function. Neuropsychobiology (2014) 70:244-52. doi: 10.1159/0003 69026

8. Hibbs AM, Storfer-Isser A, Rosen C, Ievers-Landis CE, Taveras EM, Redline S. Advanced sleep phase in adolescents born preterm. Behav Sleep Med. (2014) 12:412-24. doi: 10.1080/15402002.2013.8 25838

9. Marcus CL, Meltzer LJ, Roberts RS, Traylor J, Dix J, D’ilario J, et al. Long-term effects of caffeine therapy for apnea of prematurity on sleep at school age. Am J Respir Crit Care Med. (2014) 190:791-9. doi: 10.1164/rccm.201406-1092OC

10. Stangenes KM, Fevang SK, Grundt J, Donkor HM, Markestad T, Hysing M, et al. Children born extremely preterm had different sleeping habits at 11 
years of age and more childhood sleep problems than term-born children. Acta Paediatr. (2017) 106:1966-72. doi: 10.1111/apa.13991

11. Hibbs AM, Johnson NL, Rosen CL, Kirchner HL, Martin $\mathrm{R}$, Storfer-Isser A, et al. Prenatal and neonatal risk factors for sleep disordered breathing in school-aged children born preterm. J Pediatr. (2008) 153:176-82. doi: 10.1016/j.jpeds.2008. 01.040

12. Paavonen EJ, Strang-Karlsson S, Raikkonen K, Heinonen K, Pesonen AK, Hovi P, et al. Very low birth weight increases risk for sleepdisordered breathing in young adulthood: the helsinki study of very low birth weight adults. Pediatrics (2007) 120:778-84. doi: 10.1542/peds.20070540

13. Tapia IE, Shults J, Doyle LW, Nixon GM, Cielo CM, Traylor J, et al. Perinatal risk factors associated with the obstructive sleep apnea syndrome in schoolaged children born preterm. Sleep (2016) 39:737-42. doi: 10.5665/sleep.5618

14. American Academy of SleepMedicine. The International Classification of Sleep Disorders. 3rd ed. Darien, CT (2014).

15. Roksund OD, Clemm H, Heimdal JH, Aukland SM, Sandvik L, Markestad T, et al. Left vocal cord paralysis after extreme preterm birth, a new clinical scenario in adults. Pediatrics (2010) 126:e1569-77. doi: 10.1542/peds.2010-1129

16. Leversen KT, Sommerfelt K, Ronnestad A, Kaaresen PI, Farstad T, Skranes J, et al. Prediction of neurodevelopmental and sensory outcome at 5 years in Norwegian children born extremely preterm. Pediatrics (2011) 127:e630-8. doi: 10.1542/peds.2010-1001

17. Vollsaeter M, Roksund OD, Eide GE, Markestad T, Halvorsen T. Lung function after preterm birth: development from mid-childhood to adulthood. Thorax (2013) 68:767-76. doi: 10.1136/thoraxjnl-2012202980

18. Skjaerven R, Gjessing HK, Bakketeig LS. Birthweight by gestational age in Norway. Acta Obstet Gynecol Scand. (2000) 79:440-9. doi: 10.1080/j.1600-0412.2000.079006440.x

19. Markestad T, Kaaresen PI, Ronnestad A, Reigstad H, Lossius K, Medbo et al. Early death, morbidity, and need of treatment among extremely premature infants. Pediatrics (2005) 115:1289-98. doi: 10.1542/peds.2004-1482

20. Westby Wold SH, Sommerfelt K, Reigstad H, Ronnestad A, Medbo S, Farstad $\mathrm{T}$, et al. Neonatal mortality and morbidity in extremely preterm small for gestational age infants: a population based study. Arch Dis Child Fetal Neonatal Ed. (2009) 94:F363-7. doi: 10.1136/adc.2009.157800

21. Baumer JH, Wright D, Mill T. Illness severity measured by CRIB score: a product of changes in perinatal care? Arch Dis Child Fetal Neonatal Ed. (1997) 77:F211-5. doi: 10.1136/fn.77.3.F211

22. Scottish Neonatal Consultants Collaborative Study Group and the International Neonatal Network' Collaborative Study Group and the International Neonatal Network. CRIB (clinical risk index for babies), mortality, and impairment after neonatal intensive care. Lancet (1995) 345:1020-2. doi: 10.1016/S0140-6736(95)90758-0

23. Hirshkowitz M, Kaitlynwhiton P, Albert S, Alessi C, Bruni O, Doncarlos L, et al. National Sleep Foundation's updated sleep duration recommendations: final report. Sleep Health (2015) 1:233-43. doi: 10.1016/j.sleh.2015.10.004

24. Johnson S, Hollis C, Kochhar P, Hennessy E, Wolke D, Marlow N. Psychiatric disorders in extremely preterm children: longitudinal finding at age 11 years in the EPICure study. J Am Acad Child Adolesc Psychiatry (2010) 49:453-63 . doi: 10.1097/00004583-201005000-00006

25. Fevang SKE, Hysing M, Sommerfelt K, Elgen I. Mental health assessed by the Strengths and Difficulties Questionnaire for children born extremely preterm without severe disabilities at 11 years of age: a Norwegian, national population-based study. Eur Child Adolesc Psychiatry (2017) 26:1523-31. doi: 10.1007/s00787-017-1007-x

26. Krystal AD. Psychiatric disorders and sleep. Neurol Clin. (2012) 30:1389-1413. doi: 10.1016/j.ncl.2012.08.018

27. Li S, Jin X, Yan C, Wu S, Jiang F, Shen X. Habitual snoring in school-aged children: environmental and biological predictors. Respir Res. (2010) 11:144. doi: 10.1186/1465-9921-11-144

28. Kurjak A, Stanojevic M, Andonotopo W, Scazzocchio-Duenas E, Azumendi G, Carrera JM. Fetal behavior assessed in all three trimesters of normal pregnancy by four-dimensional ultrasonography. Croat Med J. (2005) $46: 772-80$.
29. Huang YS, Guilleminault C. Pediatric obstructive sleep apnea and the critical role of oral-facial growth: evidences. Front Neurol. (2012) 3:184. doi: 10.3389/fneur.2012.00184

30. Zhang L, Samet J, Caffo B, Punjabi NM. Cigarette smoking and nocturnal sleep architecture. Am J Epidemiol. (2006) 164:529-37. doi: 10.1093/aje/kwj231

31. Schuetze P, Eiden RD, Colder CR, Gray TR, Huestis MA. Physiological regulation in cigarette exposed infants: an examination of potential moderators. Neurotoxicol Teratol. (2011) 33:567-74. doi: 10.1016/j.ntt.2011.07.004

32. Lumeng JC, Chervin RD. Epidemiology of pediatric obstructive sleep apnea. Proc Am Thorac Soc. (2008) 5:242-52. doi: 10.1513/pats.200708-135MG

33. Felder JN, Baer RJ, Rand L, Jelliffe-Pawlowski LL, Prather AA. Sleep disorder diagnosis during pregnancy and risk of preterm birth. Obstet Gynecol. (2017) 130:573-81. doi: 10.1097/AOG.0000000000 002132

34. Bhattacharyya N. Sleep and health implications of snoring: a populational analysis. Laryngoscope (2015) 125:2413-6. doi: 10.1002/lary. 25346

35. Ross KR, Redline S. Sleep outcomes in children born prematurely. In: Respiratory Outcomes in Preterm Infants, Hibbs A, Muhlebach M. editors. Cham: Respiratory Medicine. Humana Press (2017) 161-79.

36. Emancipator JL, Storfer-Isser A, Taylor HG, Rosen CL, Kirchner HL, Johnson NL, et al. Variation of cognition and achievement with sleep-disordered breathing in full-term and preterm children. Arch Pediatr Adolesc Med. (2006) 160:203-10. doi: 10.1001/archpedi.160. 2.203

37. Gozal D. Sleep-disordered breathing and school performance in children Pediatrics (1998) 102:616-20. doi: 10.1542/peds.102.3.616

38. Gozal D, Pope, DW Jr. Snoring during early childhood and academic performance at ages thirteen to fourteen years. Pediatrics (2001) 107:1394-9. doi: 10.1542/peds.107.6.1394

39. O'brien LM, Gozal D. Behavioural and neurocognitive implications of snoring and obstructive sleep apnoea in children: facts and theory. Paediatr Respir Rev. (2002) 3:3-9. doi: 10.1053/prrv.2002. 0177

40. O'brien LM, Mervis CB, Holbrook CR, Bruner JL, Klaus CJ, Rutherford J, et al. Neurobehavioral implications of habitual snoring in children. Pediatrics (2004) 114:44-9. doi: 10.1542/peds.114.1.44

41. Halbower AC, Mahone EM. Neuropsychological morbidity linked to childhood sleep-disordered breathing. Sleep Med Rev. (2006) 10:97-107. doi: 10.1016/j.smrv.2005.10.002

42. Beebe DW, Rausch J, Byars KC, Lanphear B, Yolton K. Persistent snoring in preschool children: predictors and behavioral and developmental correlates. Pediatrics (2012) 130:382-9. doi: 10.1542/peds.20120045

43. American Academy of Pediatrics. Section on Pediatric Pulmonology and Subcommittee on Obstructive Sleep Apnea, Syndrome Clinical practice guideline: diagnosis and management of childhood obstructive sleep apnea syndrome. Pediatrics (2002) 109:704-12.

44. Wang K, Difiore JM, Martin RJ, Rosen CL, Hibbs AM. Markers for severity of illness associated with decreased snoring in toddlers born ELGA. Acta Paediatr. (2013) 102:e39-43. doi: 10.1111/apa.12033

45. Lekic T, Klebe D, Poblete R, Krafft PR, Rolland WB, Tang J, et al. Neonatal brain hemorrhage (NBH) of prematurity: translational mechanisms of the vascular-neural network. Curr Med Chem. (2015) 22:1214-38. doi: $10.2174 / 0929867322666150114152421$

46. Bardin C, Zelkowitz P, Papageorgiou A. Outcome of small-for-gestational age and appropriate-for-gestational age infants born before 27 weeks of gestation. Pediatrics (1997) 100:E4. doi: 10.1542/peds.100.2.e4

47. Sivertsen B, Harvey AG, Pallesen S, Hysing M. Trajectories of sleep problems from childhood to adolescence: a population-based longitudinal study from Norway. J Sleep Res. (2017) 26:55-63. doi: 10.1111/jsr. 12443

48. Calhoun SL, Vgontzas AN, Fernandez-Mendoza J, Mayes SD, Tsaoussoglou $\mathrm{M}$, Basta $\mathrm{M}$, et al. Prevalence and risk factors of excessive daytime sleepiness in a community sample of young children: the role of obesity, asthma, anxiety/depression, and sleep. Sleep (2011) 34:503-7. doi: 10.1093/sleep/34.4.503 
49. Cappuccio FP, Taggart FM, Kandala NB, Currie A, Peile E, Stranges $\mathrm{S}$, et al. Meta-analysis of short sleep duration and obesity in children and adults. Sleep (2008) 31:619-26. doi: 10.1093/sleep/31. 5.619

50. Gruber R, Cassoff J, Frenette S, Wiebe S, Carrier J. Impact of sleep extension and restriction on children's emotional lability and impulsivity. Pediatrics (2012) 130:e1155-61. doi: 10.1542/peds.2012-0564

51. Cappuccio FP, Miller MA. Sleep and cardio-metabolic disease. Curr Cardiol Rep. (2017) 19:110. doi: 10.1007/s11886-0170916-0

52. Fevang SK, Hysing M, Markestad T, Sommerfelt, K. Mental health in children born extremely preterm without severe neurodevelopmental disabilities. Pediatrics (2016) 137:e20153002. doi: 10.1542/peds.2015-3002
Conflict of Interest Statement: The authors declare that the research was conducted in the absence of any commercial or financial relationships that could be construed as a potential conflict of interest.

The reviewer RS and handling Editor declared their shared affiliation.

Copyright (c) 2018 Stangenes, Hysing, Fevang, Elgen, Halvorsen, Markestad and Bjorvatn. This is an open-access article distributed under the terms of the Creative Commons Attribution License (CC BY). The use, distribution or reproduction in other forums is permitted, provided the original author(s) and the copyright owner are credited and that the original publication in this journal is cited, in accordance with accepted academic practice. No use, distribution or reproduction is permitted which does not comply with these terms. 